\title{
Magnesium in drinking water supplies and mortality from acute myocardial infarction in north west England
}

\author{
R Maheswaran, S Morris, S Falconer, A Grossinho, I Perry, J Wakefield, P Elliott
}

\begin{abstract}
Objectives-To examine whether higher concentrations of magnesium in drinking water supplies are associated with lower mortality from acute myocardial infarction at a small area geographical level; to examine if the association is modified by age, sex, and socioeconomic deprivation. Design-Small area geographical study using 13794 census enumeration districts. Water constituent concentrations (magnesium, calcium, fluoride, lead) measured at water supply zone and assigned to enumeration districts.
\end{abstract}

Setting-305 water supply zones in north west England.

Subjects-Resident population of 1124623 men and 1372036 women (1991 census) aged 45 years or more.

Main outcome measure-Mortality from acute myocardial infarction, International Classification of Diseases, ninth revision (ICD-9) 410. Subsidiary analysis examined deaths from ischaemic heart disease, ICD 410-414.

Results-There were 21339 male and 17883 female deaths from acute myocardial infarction in 1990-92. Drinking water magnesium concentrations in water zones ranged from $2 \mathrm{mg} / 1$ to $111 \mathrm{mg} / 1$ (mean (SD) 19 (20) mg/1, median $12 \mathrm{mg} / 1$ ); 24\% of variation in magnesium concentrations was within zone and $76 \%$ was between zone. The relative risk of mortality from acute myocardial infarction (standardised for age, sex, and Carstairs deprivation quintile) for a quadrupling of magnesium concentrations in drinking water (for example, $20 \mathrm{mg} / 1$ v $5 \mathrm{mg} / 1)$ was $1.01(95 \%$ confidence interval (CI) 0.99 to 1.03 ). When adjusted for north-south and eastwest trends in mortality from acute myocardial infarction and for drinking water calcium, fluoride, and lead concentrations, this relative risk was 1.01 (95\% CI 0.96 to 1.06 ). There was no evidence of a protective effect for acute myocardial infarction even among age, sex, and deprivation groups that were likely to be relatively magnesium deficient. For ischaemic heart disease mortality there was an apparent protective effect of magnesium and calcium (with calcium predominating in the joint model), but these were no longer significant when the geographical trends were incorporated.
Conclusions-No evidence was found of an association between magnesium concentrations in drinking water supplies and mortality from acute myocardial infarction. These results do not support the hypothesis that magnesium is the key water factor in relation to mortality from heart disease.

(Heart 1999;82:455-460)

Keywords: magnesium; drinking water; myocardial infarction; mortality

The apparent protective effect of hard drinking water on mortality from ischaemic heart disease has been the focus of much research but it is not clear as to which factor is responsible. A strong claim has been made for magnesium as the key water factor. ${ }^{1-3}$ Several epidemiological studies have reported significant inverse associations between drinking water magnesium concentrations and mortality from ischaemic heart disease, ${ }^{4-10}$ but others have not. ${ }^{11-13}$ Seven of these studies examined the association at the geographical (ecological) level ${ }^{5-811-13}$ and three examined it at the individual level. ${ }^{4910}$ Many of these studies were, however, limited by methodological issues, particularly inadequate exposure measurement and lack of adjustment for measurement error and potential confounders.

The case for magnesium has been argued as being biologically plausible. ${ }^{1-4}$ Magnesium deficiency has been shown to predispose to cardiac arrhythmias through a variety of mechanisms. ${ }^{14-16}$ In experimentally induced myocardial infarcts, magnesium infusion has been shown to limit infarct size. ${ }^{17}$ Postmortem studies of people who died suddenly from ischaemic heart disease have found significantly lower magnesium concentrations in uninfarcted heart muscle, compared with concentrations in heart muscle from people who died from other causes. ${ }^{18} 19$ The biological evidence suggests that magnesium should protect against death from acute myocardial infarction rather than reduce the incidence of the condition. However, clinical trial evidence for intravenous magnesium as a therapeutic intervention following acute myocardial infarction is controversial. Small scale trials suggested that this intervention was effective, ${ }^{2021}$ but a large multicentre randomised controlled trial failed to show any benefit. ${ }^{22}$

The dose of magnesium from drinking water is substantially less than that used in therapeutic interventions. Furthermore, over $90 \%$ of 
oral intake of magnesium comes from food. ${ }^{3}$ However, it has been argued that bioavailability of magnesium in water is greater and may make a significant contribution in people who are relatively magnesium deficient. ${ }^{12}{ }^{4}$ In the UK, average daily magnesium intake by adults is $323 \mathrm{mg}$ for men and $237 \mathrm{mg}$ for women. ${ }^{23}$ Intake is related to social class, declining from $342 \mathrm{mg}$ in social classes I and II to $299 \mathrm{mg}$ in social classes IV and V for men, and from $261 \mathrm{mg}$ to $207 \mathrm{mg}$, respectively, for women. Reference nutrient intakes are $300 \mathrm{mg}$ per day and $270 \mathrm{mg}$ per day for men and women, respectively. ${ }^{24}$ Thus, if magnesium from drinking water does have a protective effect, it ought to be apparent among socioeconomically deprived people, especially women. However, no study has examined this issue in detail.

Changes in legislation in the UK which restricted drinking water supply zones to populations under 50000 , and which required regular monitoring of water constituents in these zones, gave us the opportunity to study the association between magnesium in drinking water supplies and mortality from acute myocardial infarction at a fine geographical scale. We planned to adjust for possible confounding factors, examine the effect of measurement error, and see if the effects of drinking water magnesium concentrations on mortality from acute myocardial infarction varied with age, sex, and socioeconomic deprivation.

\section{Methods}

A small area geographical study was carried out in the region supplied by a water company serving a population of approximately seven million people in north west England. The region was divided into 305 water supply zones, with an average population of 23000 per water zone. There were 13794 enumeration districts in the study region. Water zone digital boundaries were overlaid on enumeration districts using a geographical information system (ArcInfo). Magnesium concentrations in each water zone were routinely measured on domestic tap water samples taken from different sites. The magnesium concentration for a water zone was assigned to each enumeration district within that water zone. For enumeration districts that crossed water zone boundaries, the magnesium concentration assigned was that from the water zone which contained the population centroid for the enumeration district.

Deaths from acute myocardial infarction (International Classification of Diseases, ninth revision (ICD-9) 410) in 1990-92 among people aged 45 years or more were the main

Table 1 Magnesium, calcium, lead, and fluoride concentrations in water zones in north west England, 1990-92

\begin{tabular}{lccccc}
\hline & $\begin{array}{l}\text { Average number of } \\
\text { measurements per } \\
\text { zone }\end{array}$ & Mean (SD) & Median & Minimum & Maximum \\
\hline Magnesium $(\mathrm{mg} / \mathrm{l})$ & 16 & $19(20)$ & 12 & 2 & 111 \\
Calcium $(\mathrm{mg} / \mathrm{l})$ & 17 & $52(43)$ & 36 & 5 & 215 \\
Fluoride $(\mathrm{mg} / \mathrm{l})$ & 10 & $0.08(0.11)$ & 0.05 & 0.02 & 0.8 \\
Lead $(\mu \mathrm{g} / \mathrm{l})$ & 187 & $13(16)$ & 10 & 1 & 190 \\
\hline
\end{tabular}

outcome of interest. In a subsidiary analysis, because of the possibility of misclassification, deaths from ischaemic heart disease (ICD 410-414) were also examined. 1991 enumeration district level population data adjusted for underenumeration were used as denominators. ${ }^{25}$

Potential confounders taken into account at the enumeration district level in the analysis were age, sex, and socioeconomic deprivation. Carstairs score was used as an index of socioeconomic deprivation. This has previously been shown to predict mortality at the small area level. ${ }^{26}$ The score is a standardised combination of four variables from the 1991 census: per cent persons with no car; per cent persons in overcrowded housing; per cent persons with household head in social class IV or $\mathrm{V}$; and per cent men unemployed. In addition, potential confounding caused by calcium, fluoride, and lead in drinking water, also measured at the water zone level, was examined. Calcium was included because it is one of the main determinants of water hardness, fluoride because of a reported association with heart disease mortality, ${ }^{9}$ and lead because of its possible association with cardiovascular disease $^{27} 28$ and the substantial number of houses in parts of the study region with lead pipes. Geographical gradients in heart disease were adjusted for using a linear gradient in the grid coordinates (eastings and northings) of enumeration district population centroids. These gradients may be related to geographical gradients in temperature and other factors that could possibly confound the association between magnesium and heart disease.

\section{STATISTICAL ANALYSIS}

On the original scale there were a number of extreme values of the water variables. Such values may lead to non-robust inferences and so the data on water variables were log transformed. Random effects modelling was carried out to quantify within zone and between zone variation in the four water variables. For each variable, a mean score was derived for each water zone by averaging within that zone the log values for 1990-92. Correlation coefficients were calculated between each pair of water variables at the water zone level.

Statistical modelling was carried out using $\log$ linear Poisson regression with water zone as the unit of analysis, with adjustment for confounders at the level of enumeration district. SAS and Splus were used to carry out the statistical analyses. In the main analysis, we used expected numbers, standardised for age (five year age bands), sex, and Carstairs deprivation quintiles, as the denominator (offset), with correction for extra Poisson variability (overdispersion). We fitted a series of models to examine the effects of the four water variables separately and in various combinations. These variables and the eastings and northings for enumeration district population centroids were entered as continuous variables. Results are presented from models which included each of 


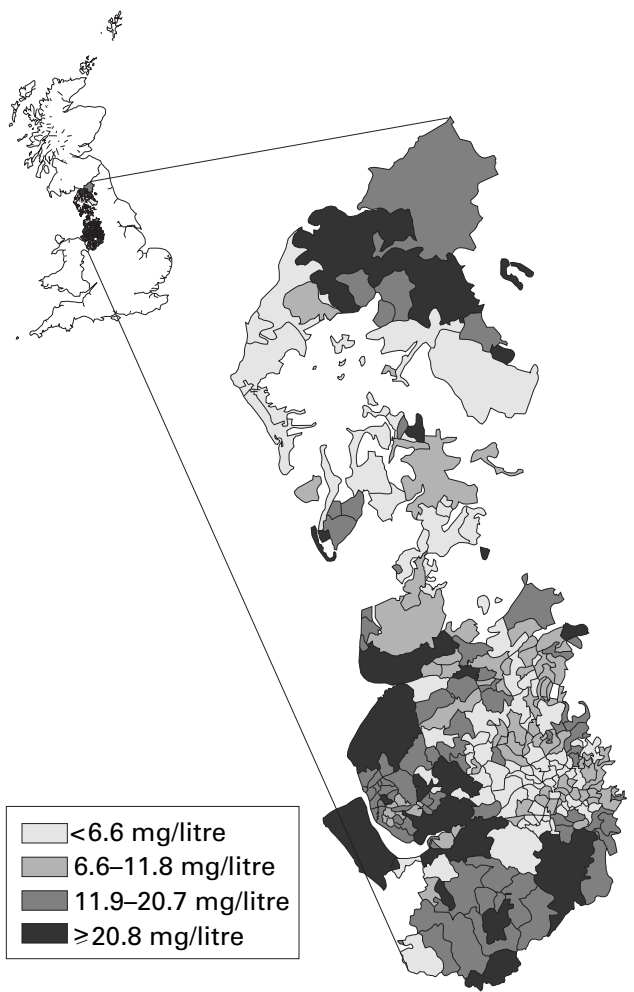

Figure 1 Average drinking (tap) water magnesium concentrations in water supply zones, north west England, 1990-92.

the four variables separately and from the model which included all four variables together.

We then carried out further analyses to see if the effect of magnesium on mortality from acute myocardial infarction varied by age, sex, and socioeconomic deprivation. For these, we used population numbers as the offset, entered age and Carstairs quintiles as categorical variables, log of magnesium as a continuous variable, and analysed data for men and women separately.

\section{Results}

There were 1124623 men and 1372036 women aged 45 years or more in the study region in 1991. A total of 21339 men and 17883 women died from acute myocardial infarction, and 33964 men and 30262 women died from ischaemic heart disease in 1990-92.
Magnesium, calcium, fluoride, and lead concentrations in drinking water are shown in table 1 . The geographical variation in magnesium concentrations is shown in fig 1 . Drinking water magnesium concentrations in water zones ranged from $2 \mathrm{mg} / 1$ to $111 \mathrm{mg} / \mathrm{l}$. For magnesium, $24 \%$ of variation was within zone and $76 \%$ was between zone. Within zone variation accounted for $20 \%, 38 \%$, and $81 \%$ of total variation for calcium, fluoride, and lead, respectively. The correlation between magnesium and calcium concentrations was 0.87 . Less strong correlations were observed between magnesium and fluoride (0.38) and calcium and fluoride (0.31). Magnesium and calcium were inversely correlated with northings $(-0.12$ and -0.27 , respectively) and eastings $(-0.36$ and -0.30 , respectively), indicating a trend for harder water in the south west of the region.

The results of the main Poisson regression analyses are shown in table 2 . The relative risk of mortality from acute myocardial infarction (standardised for age, sex, and Carstairs deprivation quintile) for a quadrupling of magnesium concentration in drinking water was 1.01 (95\% confidence interval (CI) 0.99 to 1.03 ). When adjusted for geographical gradients in mortality from acute myocardial infarction and for drinking water calcium, fluoride and lead concentrations, this relative risk remained 1.01 (95\% CI 0.96 to 1.06 ), but interpretation was complicated by the high correlation between calcium and magnesium. Calcium and fluoride appeared to have no significant association with mortality from acute myocardial infarction. There was a marginally significant inverse association with lead after adjustment for geographical gradients.

We also analysed data for each of the three years separately but found no consistent pattern for any of the water variables (not shown). Detailed statistical analysis of a subset of the data showed that adjustment for measurement error in the water variables and spatial structure of the data made little difference to the observed results (presented in a separate statistical paper on methodology). ${ }^{29}$

For ischaemic heart disease mortality, standardised for age, sex, and deprivation quintile, there was an apparent protective effect of magnesium and calcium (with calcium predominating in the joint model). However, these were

Table 2 Relative risk (95\% CI) in heart disease mortality for a quadrupling in concentrations of constituents in drinking water (for example, $20 \mathrm{mg} / \mathrm{l} v 5 \mathrm{mg} / \mathrm{l}$ of magnesium) in north west England, 1990-92

\begin{tabular}{|c|c|c|c|}
\hline & $\begin{array}{l}\text { Relative risks from separate } \\
\text { models }(95 \% \mathrm{CI})\end{array}$ & $\begin{array}{l}\text { Relative risks from separate } \\
\text { models adjusted for geographical } \\
\text { gradients }(95 \% \text { CI) }\end{array}$ & $\begin{array}{l}\text { Relative risks from combined } \\
\text { model adjusted for geographical } \\
\text { gradients }(95 \% \mathrm{CI})\end{array}$ \\
\hline \multicolumn{4}{|c|}{ Acute myocardial infarction (ICD 410) } \\
\hline Log magnesium (mg/l) & $1.01(0.99$ to 1.03$)$ & $1.01(0.98$ to 1.03$)$ & $1.01(0.96$ to 1.06$)$ \\
\hline $\log$ calcium $(\mathrm{mg} / \mathrm{l})$ & $1.02(0.99$ to 1.04$)$ & $1.00(0.97$ to 1.04$)$ & $0.99(0.94$ to 1.05$)$ \\
\hline Log fluoride $(\mathrm{mg} / \mathrm{l})$ & $0.99(0.96$ to 1.02$)$ & $1.00(0.97$ to 1.04$)$ & $0.99(0.96$ to 1.02$)$ \\
\hline Log lead $(\mu \mathrm{g} / \mathrm{l})$ & $1.00(0.96$ to 1.03$)$ & $0.94(0.91$ to 0.98$)$ & 0.94 (0.91 to 0.98$)$ \\
\hline \multicolumn{4}{|c|}{ Ischaemic heart disease (ICD 410-414) } \\
\hline Log magnesium (mg/l) & $0.97(0.96$ to 0.99$)$ & $1.00(0.98$ to 1.02$)$ & $1.01(0.96$ to 1.05$)$ \\
\hline $\log$ calcium $(\mathrm{mg} / \mathrm{l})$ & $0.96(0.94$ to 0.99$)$ & $1.00(0.97$ to 1.02$)$ & $0.98(0.94$ to 1.04$)$ \\
\hline Log fluoride (mg/l) & $1.00(0.98$ to 1.03$)$ & $1.02(0.99$ to 1.05$)$ & $1.02(0.99$ to 1.05$)$ \\
\hline Log lead $(\mu \mathrm{g} / \mathrm{l})$ & $0.98(0.95$ to 1.01$)$ & $0.99(0.96$ to 1.02$)$ & $0.99(0.96$ to 1.03$)$ \\
\hline
\end{tabular}

Results from Poisson regression analyses with expected numbers standardised for age, sex, and Carstairs deprivation quintile. CIs are adjusted with overdispersion parameters ( 1.6 for acute myocardial infarction and 1.9 for ischaemic heart disease). 

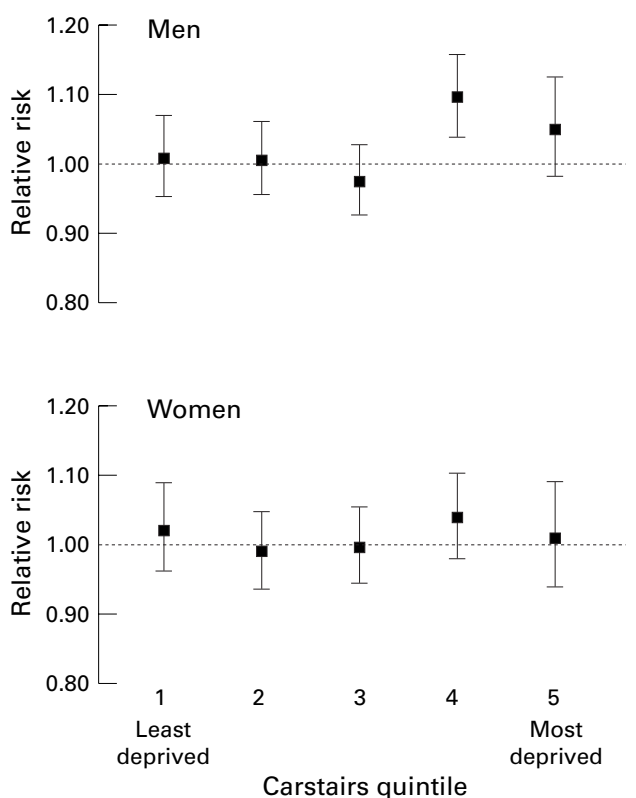

Figure 2 Age adjusted relative risk (95\% CI) of mortality from acute myocardial infarction by socioeconomic deprivation quintile, for a quadrupling in drinking water magnesium concentrations (for example, $20 \mathrm{mg} / \mathrm{l} v 5 \mathrm{mg} / \mathrm{l}$ ), north west England, 1990-92.
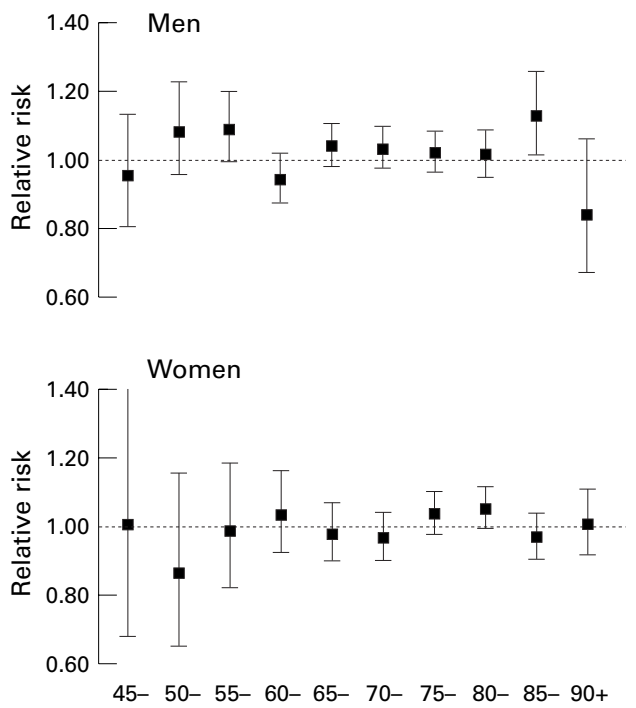

Age (years)

Figure 3 Socioeconomic deprivation adjusted relative risk (95\% CI) of mortality from acute myocardial infarction by age, for a quadrupling in drinking water magnesium concentrations (for example, $20 \mathrm{mg} / \mathrm{l} v 5 \mathrm{mg} / \mathrm{l}$ ), north west England, 1990-92.

no longer significant when geographical trends in ischaemic heart disease mortality were taken into account (table 2).

Figure 2 shows the effect of magnesium on acute myocardial infarction mortality by sex and deprivation category. There was no evidence of a protective effect of magnesium even among women living in socioeconomically deprived areas. Figure 3 shows the effect of magnesium on acute myocardial infarction mortality in different age groups. Even among retired people, whose drinking water magnesium intake might be more accurately reflected by water supply levels to their place of residence than people of working age, there was no clear evidence of a protective effect of magnesium.

\section{Discussion}

We found no evidence to support an association between magnesium concentrations in drinking water supplies and mortality from acute myocardial infarction in north west England. We also found no association between ischaemic heart disease mortality and magnesium concentrations once confounding and geographical factors had been taken into account.

Our results do not appear to be consistent with four geographical level ${ }^{5-8}$ and three individual level ${ }^{410}$ epidemiological studies that found inverse associations between magnesium in drinking water and heart disease mortality. These studies were carried out in Sweden, Finland, USA, Canada, and South Africa. However, two large geographical studies that found no evidence to support this association were both carried out in the UK. ${ }^{11} 12$

It is possible that in countries with low concentrations of magnesium in the drinking water there is no protective effect. However, the range of exposures in our study was similar to that in several studies reporting inverse associations, including studies in Sweden and Finland in which drinking water magnesium concentrations ranged from $1.3-20 \mathrm{mg} / 1,0-15 \mathrm{mg} / \mathrm{l}$, and $0.6-27.8 \mathrm{mg} / 1$, respectively. ${ }^{48}{ }^{10}$ Mean and median concentrations in a large study in the USA were likewise comparable at 9.8 and $6.2 \mathrm{mg} / \mathrm{l}$, respectively. ${ }^{5}$

It is possible that magnesium has differential effects in different parts of the world because of differences in underlying risk or because co-factors need to be present for it to exert a protective effect. Canada and the USA have lower mortality rates from acute myocardial infarction compared with England, but Sweden and Finland have similar or higher rates, so there are no consistent patterns in relation to underlying heart disease mortality risk. ${ }^{30}$

Another possible explanation is that magnesium is only likely to have an effect in countries where dietary intake of magnesium is relatively low. However, studies suggest that 24 hour urinary magnesium excretion, an indirect indicator of magnesium intake in the steady state, in the UK is similar to that in Finland, Canada, and the USA. ${ }^{31}$

The contribution of drinking water magnesium to overall magnesium intake is generally about $10 \%$. $^{3}$ Survey results suggest that the average intake of liquid in England and Wales is 1.6 litres per day, of which $73 \%$ is from tap water. $^{32}$ For a drinking water magnesium content of $20 \mathrm{mg} / \mathrm{l}$, the intake from tap water would be $23 \mathrm{mg}$ per day, constituting on average about $7 \%$ of oral magnesium intake for men and $10 \%$ for women in the UK. It has been argued that bioavailability of magnesium is greater from water than from food, and experiments suggest that up to $40-50 \%$ of waterborne magnesium may be absorbed compared with $33 \%$ from food. ${ }^{1}$ This should increase the relative importance of waterborne magnesium, 
particularly for people whose diets are relatively deficient in magnesium. However, even among women living in socioeconomically deprived areas, who tend to have a low dietary magnesium intake, we found no evidence of a protective effect in relation to acute myocardial infarction mortality. A postmortem study based on small numbers suggested that myocardial magnesium concentrations were higher in areas supplied with hard water compared with areas with soft water supplies, ${ }^{33}$ but other studies have failed to replicate this finding. ${ }^{34-36}$

We examined heart disease mortality in relation to concurrent drinking water magnesium concentrations but this is unlikely to have introduced substantial error as intracellular concentrations of magnesium change within a few weeks of changes in oral intake of magnesium. ${ }^{37-39}$

Errors in exposure measurement can attenuate true underlying associations, but even when this was taken into account using multilevel statistical models we found no evidence of a significant protective effect. ${ }^{29}$ As ours is an ecological study, the possibility of ecological bias cannot be ruled out - that is, the association observed at the area level is different from that which exists at the individual level - and may explain the anomalous finding between lead concentrations and heart disease. If within zone variation accounted for most of the variation in water constituents, it would have been difficult to detect any association with heart disease mortality. However, this was not an important limitation to our study as a substantial amount of the variation in magnesium was between zones. Drinking water magnesium intake might have been misclassified among working people, as a significant amount of water consumption might have been at the workplace while exposure was classified on the basis of their place of residence. However, even among the population over retirement age, there was little evidence in support of a protective effect.

Several of the ecological studies finding inverse associations between magnesium in drinking water and heart disease mortality carried out simple parametric or non-parametric correlations and did not adjust for any confounders. ${ }^{5-8}$ Cohort and case control studies did not adjust for possible socioeconomic confounding. ${ }^{410}$ In addition, none of the studies adjusted for general geographical trends in heart disease mortality. These trends, which may be related to gradients in temperature, socioeconomic conditions, and other factors, may have confounded reported associations between magnesium and heart disease mortality.

Another important difference between our study and previous geographical studies on magnesium and heart disease mortality is that we examined data on a fine areal scale, with total water zone populations not exceeding 50000 . With regard to water hardness, whether or not an inverse association is found appears to be linked to the geographical scale on which the study is carried out. Studies based on large geographic areas-for example, counties-were usually able to show an inverse association, but this was not generally the case for studies based on small geographical areasfor example, areas within cities. ${ }^{40}$ Studies based on large areas are usually unable to adjust adequately for socioeconomic confounding.

While we did detect a marginally significant inverse association of both magnesium and calcium concentrations and ischaemic heart disease mortality, these did not persist once adjustment was made for geographical trends. Such adjustments for geographical gradients, however, need to be interpreted cautiously as they might result in over fitting statistical models and spuriously removing effects. Nevertheless, our findings and the limitations of previously published studies raise questions about the epidemiological basis for magnesium as the key water factor.

Our study has addressed several of the limitations inherent in previous studies and is one of the most detailed ecological studies to date on the subject, carried out at the small area scale. We have taken into account a range of potential confounders including socioeconomic deprivation, age, sex, other water constituents, and general geographical trends in heart disease mortality, and examined the effect of measurement error on the results. In addition, we specifically examined the association between drinking water magnesium concentrations and acute myocardial infarction mortality in population subgroups in whom any protective effect might be most apparent. In conclusion, our results do not support the hypothesis that magnesium is the key water factor in relation to mortality from heart disease. Further studies only appear indicated if they can provide substantially improved exposure information, preferably with long term follow up at the individual level.

We thank Dr Keith Osborn of North West Water for providing the exposure data and specialist advice on interpretation of water quality measurements. We thank the Office for National Statistics for making postcoded mortality data available to us. This work uses data provided with the support of the ESRC and JISC, and census and boundary material which are copyright of the Crown, the Post Office and the ED-LINE Consortium. The the Crown, the Post Office and the ED-LINE Consortium. The Small Area Health Statistics Unit is funded by a grant from the Department of Health, Department of the Environment, Health and Safety Executive, Scottish Office Home and Health Department, Welsh Office, and Northern Ireland Department of Health and Social Services. This work was also supported by a grant from the Wellcome Trust, UK. The views expressed in
this paper are those of the authors and not necessarily those of the funding departments.

1 Marier JR. Cardio-protective contribution of hard waters to magnesium intake. Rev Can Biol 1978;37:115-25.

2 Durlach J, Bara M, Guiet-Bara A. Magnesium level in drinking water and cardiovascular risk. Magnesium 1985;4: 5-15.

3 Marx A, Neutra RR. Magnesium in drinking water and ischaemic heart disease. Epidemiol Rev 1997;19:258-72.

4 Rubenowitz E, Axelsson G, Rylander R. Magnesium in drinking water and death from acute myocardial infarction. Am $\mathcal{F}$ Epidemiol 1996;143:456-62.

5 Schroeder HA. Relation between mortality from cardiovascular disease and treated water supplies. $\mathscr{f} A M A 1960 ; 172$ 1902-8.

6 Anderson TW, le Riche WH. Sudden death from ischaemic heart disease in Ontario and its correlation with water hardness and other factors. Can Med Assoc f 1971;105: 155-60.

7 Leary WP, Reyes AJ, Lockett CJ, et al. Magnesium and deaths ascribed to ischaemic heart disease in South Africa. S Afr Med F 1983;64:775-6.

8 Rylander R, Bonevik H, Rubenowitz E. Magnesium and calcium in drinking water and cardiovascular mortality. Scand $\mathcal{F}$ Work Environ Health 1991;17:91-4. 
9 Luoma H, Aromaa A, Helminen S, et al. Risk of myocardial infarction in Finnish men in relation to fluoride, magneMed Scand 1983;213:171-6.

10 Punsar S, Karvonen MJ. Drinking water quality and sudden death: observations from West and East Finland. Cardiology 1979;64:24-34

11 Shaper AG, Packham RF, Pocock SJ. The British regional heart study: cardiovascular mortality and water quality. $\mathcal{F}$ Environ Pathol Toxicol 1980;4-2,3:89-111.

12 Crawford MD, Gardner MJ, Morris JN. Mortality and hardness of local water supplies. Lancet 1968;i:827-31.

13 Nerbrand C, Svardsudd K, Ek J, et al. Cardiovascular mortality and morbidity in seven counties in Sweden in relation to water hardness and geological settings. Eur Heart $\mathcal{f}$ 1992;13:721-7.

14 Turlapaty PDMV, Altura BM. Magnesium deficiency produced spasms of coronary arteries: relationship to etiol-
ogy of sudden death ischaemic heart disease. Science 1980; 208: $198-200$.

15 Eisenberg MJ. Magnesium deficiency and cardiac arrhythmias. N Y State f Med 1986;86:133-5.

16 Sjogren A, Edvinsson L, Fallgren B. Magnesium deficiency in coronary artery disease and cardiac arrhythmias. F Intern Med 1989;226:213-22.

17 Baxter GF, Sumeray MS, Walker JM. Infarct size and magnesium: insights into LIMIT-2 and ISIS-4 from experimental studies. Lancet 1996;348:1424-6.

18 Chipperfield B, Chipperfield JR. Heart muscle magnesium, potassium and zinc concentrations after sudden death from heart disease. Lancet 1973;ii:293-6.

19 Elwood PC. Myocardial magnesium and ischaemic heart disease. Artery 1981;9:200-4.

20 Teo KK, Yusuf S, Collins R, et al. Effect of intravenous magnesium in suspected acute myocardial infarction: overview of randomised trials. BMF 1991;303:1499-503.

21 Woods KL, Fletcher S, Roffe C, et al. Intravenous magnesium sulphate in suspected acute myocardial infarction: results of the second Leicester intravenous maginfarction: results of the second Leicester intravenous magnesium $1553-8$.

22 ISIS-4 Collaborative Group. ISIS-4: a randomised factorial trial assessing early oral captopril, oral mononitrate and intravenous magnesium sulphate in 58,050 patients with suspected acute myocardial infarction. Lancet 1995;345: 669-85.

23 Gregory J, Foster K, Tyler H, et al. The dietary and nutritional survey of British adults. London: HMSO, 1990.

24 Department of Health. Dietary reference values for food energy and nutrients for the United Kingdom. London: HMSO, 1991.
25 Anon. Estimating with confidence: mid-1991 population estimates for small areas. Population Trends 1995;82:6.

26 Carstairs V, Morris R. Deprivation and health in Scotland. Health Bull 1990;48:162-75.

27 Pirkle JL, Schwartz J, Landis JR, et al. The relationship between blood lead levels and blood pressure and its cardiovascular risk implications. Am f Epidemiol 1985;121: 246-58.

28 Maheswaran R, Gill JS, Beevers DG. Blood pressure and industrial lead exposure. Am f Epidemiol 1993;137:645-53.

29 Wakefield J, Morris S. Spatial dependence and errors-invariables in environmental epidemiology. In: Bernardo JM, Berger JO, Dawid AP, et al, eds. Bayesian statistics 6. Oxford: Oxford University Press. [In press]

30 World Health Organization. World health statistics annual 1995. Geneva: World Health Organization, 1996.

31 INTERSALT appendix tables. F Hum Hypertens 1989;3: 331-407.

32 MEL Research. Tap water consumption in England and Wales: findings from the 1995 national survey. Birmingham: MEL Research, 1996.

33 Anderson TW, Neri LC, Schreiber GB, et al. Ischaemic heart disease, water hardness and myocardial magnesium. Can Med Assoc F 1975;113:199-203.

34 Chipperfield B, Chipperfield JR, Behr G, et al. Magnesium and potassium content of normal heart muscle in areas of hard and soft water. Lancet 1976;i:121-2.

35 Chipperfield B, Chipperfield JR. Relation of myocardial metal concentrations to water hardness and death rates from ischaemic heart disease. Lancet 1979;ii:709-12.

36 Elwood PC, Sweetnam PM, Beasley WH, et al. Magnesium and calcium in the myocardium: cause of death and area differences. Lancet 1980;ii:720-2.

37 Andon MB, Ilich JZ, Tzagournis MA, et al. Magnesium balance in adolescent females consuming a low- or highcalcium diet. Am f Clin Nutr 1996;63:950-3.

38 Sjogren A, Floren $\mathrm{CH}$, Nilsson A. Oral administration of magnesium hydroxide to subjects with insulin-dependent diabetes mellitus: effects on magnesium and potassium levels and on insulin requirements. Magnesium 1988;7:11722.

39 Dorup I, Skajaa K, Thybo NK. Oral magnesium supplementation restores the concentrations of magnesium, potassium and sodium-potassium pumps in skeletal muscle of patients receiving diuretic treatment. F Intern Med 1993; 233:117-23.

40 Comstock GW. Water hardness and cardiovascular disease. Am f Epidemiol 1979;110:375-400. 